\title{
Pelatihan Kader Kesehatan Remaja untuk Meningkatkan Capaian Indikator Sehat Siswa/I di Pondok Pesantren
}

\author{
Inggriane Puspita Dewi ${ }^{1}$, Santy Sanusi ${ }^{2}$, \\ Imas Maryati ${ }^{3}$ \\ ${ }^{1,2}$ Sekolah Tinggi Ilmu Kesehatan Aisyiyah Bandung \\ ${ }^{3}$ Pondok Pesantren Baiturahman-Ciparay \\ ${ }^{1}$ Email: ine.stikes12@gmail.com \\ ${ }^{2}$ Email: santysanusi1410@gmail.com \\ ${ }^{3}$ Email: ponpesbaiturahman@gmail.com
}

\begin{abstract}
ABSTRAK
Usaha Kesehatan Sekolah (UKS) adalah usaha untuk membina dan mengembangkan kebiasaan dan perilaku hidup sehat pada peserta didik usia sekolah yang dilakukan secara menyeluruh (komprehensif) dan terpadu (integrative). Hasil pengkajian awal bekerjasama dengan tim UKS pondok pesantren Baiturahman-Ciparay, didapatkan data angka kesakitan yang dialami siswa secara umum baik SMP maupun SMA adalah 43\% mengeluh batuk-pilek, $15 \%$ mual-muntah, 30\% demam tinggi, lain-lain $12 \%$, dari total jumlah siswa/i sebanyak 430 orang. Selain itu wawancara secara acak, beberapa siswa/i merasa tidak nyaman berada di asrama dan jauh dari orangtua. Pihak pondok pesantren telah berupaya untuk menekan angka kesakitan, salah satunya dengan membentuk kader kesehatan remaja (KKR), terdiri dari peserta didik yang dipilih guru guna ikut melaksanakan sebagian usaha pelayanan kesehatan terhadap diri sendiri, teman peserta didik pada khususnya dan sekolah pada umumnya, belum ada pelatihan yang terstruktur berdasarkan kurikulum kesehatan remaja. tujuan dari pengabdian masyarakat yang dilakukan ialah memberikan pelatihan pada KKR agar mampu meningkatkan pengetahuan dan keterampilan KKR untuk meningkatkan capaian indikator sehat yang telah ditetapkan oleh UKS. Kegiatan pelatihan meliputi pemberian materi, praktik serta demonstrasi keterampilan seperti P3K, penanganan kasus diare, identifikasi siswa/i yang sakit fisik dan psikososial, serta simulasi bencana alam. Pelatihan berlangsung selama 8 bulan dengan hasil menunjukkan adanya penurunan angka kesakitan siswa/i, presensi kelas meningkat, wawasan siswa/i tentang perilaku sehat meningkat. Kesimpulan : kegiatan pelatihan kader kesehatan remaja menjadi unsur yang penting dalam upaya mewujudkan perilaku hidup sehat siswa/i di asrama dan sekolah. Sarannya kegiatan sejenis dengan tema yang berbeda dapat dilanjutkan.
\end{abstract}

Kata Kunci: Usaha Kesehatan Sekolah, Kader Kesehatan Remaja

\begin{abstract}
Usaha Kesehatan Sekolah (UKS) is an effort to foster and develop habits and healthy living behaviors for school-age students who are conducted comprehensively and integrated (integrative). Preliminary assessment results in collaboration with the UKS team Baiturahman-Ciparay Islamic boarding school, obtained data on morbidity rates experienced by students in general both junior and senior high school is $43 \%$ complained of colds, $15 \%$ nausea-vomiting, $30 \%$ high fever, others $12 \%$, the total number of students as 430 people. In addition to random interviews, some students felt uncomfortable in the dormitory and away from parents. Baiturahman Islamic boarding schools have tried to reduce the number of morbidities, one of them is by forming a youth health (kader kesehatan remaja/KKR), consisting of students chosen by the teacher to participate in part of the health care business to themselves, friends of students in particular and schools in general, not yet there is structured training based on the youth health curriculum. The purpose of community service is to provide training to the KKR in order to be able to increase the knowledge and skills of the KKR to improve the achievements of the health indicators set by the UKS. Training activities include the provision of materials, practices, and demonstration of skills such as first aid, handling of diarrhea cases, identification of students who are physically and psychosocially ill, and simulating natural
\end{abstract}


disasters. The training lasted for 8 months with the results showing a decrease in student morbidity rates, increased class attendance, students' insights about healthy behavior improved. Conclusion: the training activities of KKR become an important element in the effort to realize the healthy life behaviors of students in dormitories and schools. Suggestions for similar activities with different themes can be continued.

Keywords: UKS, school, youth health

\section{PENDAHULUAN}

Usaha Kesehatan Sekolah (UKS) adalah usaha untuk membina dan mengembangkan kebiasaan dan perilaku hidup sehat pada peserta didik usia sekolah yang dilakukan secara menyeluruh (komprehensif) dan terpadu (integrative). Untuk optimalisasi program UKS perlu ditingkatkan peran serta peserta didik sebagai subjek dan bukan hanya objek. Dengan UKS ini diharapkan mampu menanamkan sikap dan perilaku hidup sehat pada dirinya sendiri dan mampu menolong orang lain. Tujuan Usaha Kesehatan Sekolah (UKS) adalah untuk meningkatkan mutu pendidikan dan prestasi belajar peserta didik dengan meningkatkan perilaku hidup bersih dan sehat serta derajat kesehatan peserta didik dan menciptakan lingkungan yang sehat, sehingga memungkinkan pertumbuhan dan perkembangan yang harmonis dan optimal dalam rangka pertumbuhan manusia Indonesia seutuhnya. Sedangkan secara khusus tujuan UKS adalah untuk memupuk kebiasaan hidup sehat dan mempertinggi derajat kesehatan peserta didik.

Pondok pesantren Baiturahman merupakan sekolah yang memiliki kurikulum pendidikan nasional dan departemen agama, sehingga mewajibkan siswa/siswinya untuk mondok tau mukim di pesantren tersebut. Jumlah siswa/siswi meliputi SMP dan SMA, sebanyak 430 orang. Jumlah siswa/i yang banyak tersebut beresiko mengalami masalah kesehatan. Hasil pengkajian awal bekerjasama dengan tim UKS Baiturahman, didapatkan data angka kesakitan yang dialami siswa secara umum baik SMP maupun SMA adalah $43 \%$ mengeluh batuk-pilek, $15 \%$ mual-muntah, $30 \%$ demam tinggi, lain-lain $12 \%$. Selain itu wawancara secara acak, beberapa siswa/i merasa tidak nyaman berada di asrama dan jauh dari orangtua.

Pihak pondok pesantren telah berupaya untuk menekan angka kesakitan, salah satunya dengan membentuk kader kesehatan remaja $(K K R)$, terdiri dari peserta didik yang dipilih guru guna ikut melaksanakan sebagian usaha pelayanan kesehatan terhadap diri sendiri, teman peserta didik pada khususnya dan sekolah pada umumnya. Kader Kesehatan Remaja (KKR) juga diartikan kader yang memiliki pengetahuan tentang kesehatan remaja yang mau membantu bersama-sama memecahkan permasalahan kesehatan khususnya pada remaja. Pihak UKS pondok pesantren Baiturahman belum memiliki kurikulum untuk pelatihan kader kesehatan serta SDM pelaksana kegiatan. Adapun tujuan dari pengabdian masyarakat yang dilakukan ialah memberikan pelatihan pada KKR agar mampu meningkatkan pengetahuan dan keterampilan KKR untuk meningkatkan capaian indikator sehat yang telah ditetapkan oleh UKS pondok pesantren Baiturahman, meliputi sehat jasmani, sehat akal serta sehat mental-spiritual.

Pemerintah Indonesia telah mencanangkan program UKS sebagai bagian dari upaya meningkatkan derajat kesehatan masyarakat, sehingga sekolah termasuk pondok pesantren memiliki kewajiban untuk melaksanakan program tersebut, namun perlu dukungan tenaga kesehatan agar program bisa terlaksana dengan baik. 


\section{Bahan dan Metode}

Kegiatan pelatihan KKR ini dilaksanakan secara rutin setiap pekan pertama, mulai bulan Januari 2018 s.d bulan Agustus 2018, di ponpes Baiturahman. Adapun bahan dan metode, sesuai dengan tema pelatihan dan disesuaikan dengan indikator sehat pada remaja, dapat dilihat pada tabel dibawah ini :

\section{Tabel 1.}

Jenis dan Pelaksanaan Kegiatan Pelatihan KKR

\begin{tabular}{|c|c|c|c|c|}
\hline NO & Kegiatan & Tujuan & Bahan & Pelaksanaan \\
\hline 1 & $\begin{array}{l}\text { Pengkajian siswa/i } \\
\text { sakit }\end{array}$ & $\begin{array}{l}\text { KKR mampu } \\
\text { melakukan } \\
\text { pengkajian } \\
\text { awal santri } \\
\text { yang sakit }\end{array}$ & $\begin{array}{l}\text { 1. Kertas HVS } \\
\text { 2. Pulpen } \\
\text { 3. Termometer } \\
\text { 4. Jam tangan }\end{array}$ & $\begin{array}{l}\text { Minggu ke-1 bulan Januari } \\
2018 \\
\text { Metode ceramah, diskusi } \\
\text { dan demonstrasi }\end{array}$ \\
\hline 2 & $\begin{array}{c}\text { Tatalaksana kasus } \\
\text { luka akibat jatuh }\end{array}$ & $\begin{array}{l}\text { KKR mampu } \\
\text { melakukan } \\
\text { pertolongan pertama } \\
\text { pada santri yang } \\
\text { terluka }\end{array}$ & $\begin{array}{l}\text { 1. Kassa gulung } \\
\text { 2. Kassa steril } \\
\text { 3. rivanol } \\
\text { 4. Betadin } \\
\text { 5. Plester } \\
\text { 6. gunting }\end{array}$ & $\begin{array}{l}\text { Minggu ke- } 1 \text { bulan } \\
\text { Februari } 2018 \\
\text { Metode ceramah, diskusi } \\
\text { dan demonstrasi }\end{array}$ \\
\hline 3 & $\begin{array}{l}\text { Tatalaksana kasus } \\
\text { gawat darurat }\end{array}$ & $\begin{array}{l}\text { KKR mampu } \\
\text { melakukan P3K } \\
\text { pada kasus tersedak, } \\
\text { pingsan, luka bakar }\end{array}$ & $\begin{array}{l}\text { 1. blankar } \\
\text { 2. collar neck } \\
\text { 3. kassa }\end{array}$ & $\begin{array}{l}\text { Minggu ke- } 1 \text { bulan } \\
\text { Maret } 2018 \\
\text { Metode ceramah, diskusi } \\
\text { dan demonstrasi }\end{array}$ \\
\hline 4 & $\begin{array}{l}\text { Pengkajian kasus } \\
\text { psiko-sosial }\end{array}$ & $\begin{array}{l}\text { KKR menjadi } \\
\text { fasilitator dalam } \\
\text { mengkaji masalah } \\
\text { psiko-sosial remaja }\end{array}$ & $\begin{array}{l}\text { 1. kertas HVS } \\
\text { 2. pulpen } \\
\text { 3. buku catatan }\end{array}$ & $\begin{array}{l}\text { Minggu ke-1 bulan } \\
\text { April } 2018 \\
\text { Metode ceramah, diskusi } \\
\text { dan demonstrasi }\end{array}$ \\
\hline 5 & $\begin{array}{l}\text { Tatalaksana kasus } \\
\text { diare }\end{array}$ & $\begin{array}{l}\text { KKR mampu } \\
\text { memberikan } \\
\text { pertolongan } \\
\text { pertama pada } \\
\text { kasus dehidrasi } \\
\text { ringan }\end{array}$ & $\begin{array}{ll}\text { 1. } & \text { air } \\
\text { 2. } & \text { gula } \\
\text { 3. } & \text { garam } \\
\text { 4. } & \text { sendok } \\
\text { 5. } & \text { gelas }\end{array}$ & $\begin{array}{l}\text { Minggu ke- } 1 \text { bulan } \\
\text { Mei } 2018 \\
\text { Metode ceramah, diskusi } \\
\text { dan demonstrasi }\end{array}$ \\
\hline 6 & $\begin{array}{l}\text { Simulasi bencana } \\
\text { Alam }\end{array}$ & $\begin{array}{l}\text { KKR mampu } \\
\text { menguasai teknik } \\
\text { menghadapi } \\
\text { bencana alam }\end{array}$ & $\begin{array}{ll}\text { 1. } & \text { pita } \\
\text { 2. } & \text { kertas warna } \\
\text { warni } \\
\text { 3. } & \text { peluit }\end{array}$ & $\begin{array}{l}\text { Minggu ke-1 bulan } \\
\text { Juni } 2018 \\
\text { Metode ceramah, diskusi dan } \\
\text { demonstrasi }\end{array}$ \\
\hline 7 & $\begin{array}{l}\text { Pencegahan } \\
\text { penggunaan } \\
\text { NAPZA }\end{array}$ & $\begin{array}{l}\text { KKR memahami } \\
\text { bahaya } \\
\text { narkoba/NAPZA }\end{array}$ & $\begin{array}{l}\text { 1. leaflet } \\
\text { 2. infocus } \\
\text { 3. laptop }\end{array}$ & $\begin{array}{l}\text { Minggu ke- } 1 \text { bulan } \\
\text { Juli } 2018 \\
\text { Metode ceramah, dan diskusi }\end{array}$ \\
\hline 8 & $\begin{array}{l}\text { Kesehatan } \\
\text { reproduksi remaja }\end{array}$ & $\begin{array}{l}\text { KKR memahami } \\
\text { kesehatan } \\
\text { reproduksi remaja }\end{array}$ & $\begin{array}{l}\text { 1. leaflet } \\
\text { 2. infocus } \\
\text { 3. laptop }\end{array}$ & $\begin{array}{l}\text { Minggu ke- } 1 \text { bulan } \\
\text { Agustus } 2018 \\
\text { Metode ceramah, dan diskusi }\end{array}$ \\
\hline
\end{tabular}

Teknis sosialisasi program dilaksanakan bulan Desember 2017, pada hari Jum'at setelah siswa menyelesaikan jadwal sekolahnya, melibatkan tim pengabdian masyarakat STIKes Aisyiyah beserta mahasiswa tingkat dua. Kegiatan dilaksanakan di UKS, halaman masjid dan lapangan olahraga pondok pesantren Baiturahman, mulai pukul 15.30 s.d $18.00 \mathrm{WIB}$. 


\section{HASIL}

Dampak kegiatan ini dapat dilihat dari evaluasi kegiatan UKS berupa perubahan angka kunjungan sakit ke UKS serta buku catatan wali asrama tentang perkembangan psikologis dan sosial santri, serta mengacu kepada indikator sehat siswa/i pondok pesantren Baiturahman yaitu:

1. Sehat jasmani dengan indikator angka kesakitan menurun (66 \% tahun 2017 menjadi 52\% per bulan Januari-Agustus 2018)

2. Sehat akal dengan indikator presensi siswa/i di kelas ( $89 \%$ menjadi $95 \%$ ), presensi dijadikan indikator dengan alasan kehadiran di kelas menunjukan kesiapan akal siswa/i untuk menuntut ilmu (mencerdaskan akal).

3. Sehat mental-spiritual dengan indikator kasus bullying di sekolah menurun $(30 \%$ menjadi $10 \%$ )

\section{PEMBAHASAN}

Tujuan adanya unit usaha kesehatan sekolah adalah menanamkan sikap dan perilaku hidup sehat pada dirinya sendiri dan mampu menolong orang lain. Kader Kesehatan Remaja (KKR) dituntut memiliki pengetahuan tentang kesehatan remaja yang mau membantu bersama-sama memecahkan permasalahan kesehatan khususnya pada remaja

Melalui aktivitas pelatihan KKR, menjadi media bagi kader kesehatan remaja untuk meningkatkan pengetahuan dan keterampilannya saat menghadapi kasus-kasus kesehatan di kalangan remaja. Pengetahuan diberikan melalui pemberian materi serta keterampilan diperoleh dengan cara melakukan praktik mulai identifikasi siswa/i yang sakit sampai dengan penanganan yang dapat dilakukan pada tahap pertolongan pertama, kader juga diberikan pengetahuan tentang cara merujuk atau melaporkan kasus yang tidak mampu ditangani sendiri.

Pihak pondok pesantren (ponpes) yang mewajibkan seluruh siswa/i nya mukim di pesantren, mendorong seluruh elemen sekolah untuk senantiasa memperhatikan kesehatan fisik, akal dan mental-spiritualnya, adanya kader kesehatan membantu pihak ponpes dalam menyebarkan informasi serta kebiasaan hidup sehat di asrama .

Tema-tema yang diberikan dalam pelatihan sesuai dengan pedoman pembinaan usaha kesehatan sekolah serta disesuaikan dengan kebutuhan remaja. Tema pengkajian siswa/i yang sakit, penanganan kasus gawat darurat, diare, pencegahan penyalahgunaan NAPZA serta kesehatan reproduksi adalah bagian dari upaya mencegah angka kesakitan serta meningkatkan indikator capaian sehat jasmani, sementara untuk kesehatan akal - mental dan spiritual, materi yang diberikan adalah upaya identifikasi gejala masalah psikososial remaja, seperti terlihat murung, sering menyendiri, mudah marah atau amuk., serta materi kesehatan mental-spiritual pada remaja. Aktivitas lain yang dilakukan oleh tim pengmas STIKes Aisyiyah adalah memberikan pembekalan serta melibatkan para wali asrama dalam kegiatan pelatihan ini.

Seluruh kegiatan dapat dilaksanakan dengan baik dan seluruh wali asrama sangat kooperatif. Manfaat kegiatan ini adalah untuk meningkatkan pengetahuan dan keterampilan kader kesehatan remaja . Inti kegiatan ini adalah pemberian materi, praktik dan evaluasi. 


\section{SIMPULAN DAN SARAN}

Pelatihan kader kesehatan remaja (KKR) menjadi hal yang penting dalam kegiatan Usaha Kesehatan Sekolah (UKS) karena terbukti dapat meningkatkan capaian indikator kesehatan sekolah. Langkah kedepan yang bisa dilakukan untuk semakin meningkatkan kemampuan kader kesehatan remaja adalah pelatihan dibuat lebih sering, sebulan 2 kali, serta kader diberikan kepercayaan untuk membina kelompok-kelompok kecil siswa/i santri untuk menjaga membiasakan perilaku hidup sehat.

\section{UCAPAN TERIMA KASIH}

Pelaksanaan pengabdian masyarakat dan penyusunan laporan ini, tidak terlepas dari peran serta pihak-pihak yang terkait, yaitu:

1. Ketua STIKes Aisyiyah Bandung

2. Lembaga BP2MPK STIKes Aisyiyah Bandung

3. Dosen- dosen program studi Sarjana Keperawatan STIKes Aisyiyah Bandung

4. Pondok pesantren Baiturrahman yang menjadi mitra pengmas

5. Mahasiswa tingkat II yang telah terlibat dalam tim pengabdian masyarakat Serta seluruh pihak yang tidak bisa penulis sebutkan satu persatu semoga kebaikan ini mendapat pahala dari Allah Subhanallahu wa ta'ala.

\section{DAFTAR PUSTAKA}

KEMENKES.2015. Pedoman Akselerasi Pembinaan dan Pelaksana UKS http://kesga.kemkes.go.id/images/pedoman/pedoman\%20aksel\%20UKS-2016.pdf

Ridwan, Dwi Noerjoedianto,Andy Amir.2016. Penerapan Metode Tutor Sebaya Bagi Kader Kesehatan Remaja Siswa Sma Di Kota Jambi Tahun. Jurnal Pengabdian pada Masyarakat,31 (1).

KEMENDIKBUD.2012. Pedoman pembinaan pengembangan Usaha Kesehatan Sekolah http://www.mebermutu.org/admin/lampiran/pedoman-pembinaan-uks.pd 